\title{
Laboreal
}

Volume $4 \mathrm{~N}^{\circ} 1$ | 2008

Ergologia, trabalho, desenvolvimentos

\section{Glossário da ergologia}

Glosario de la ergología

Vocabulaire ergologique

Glossary of ergology

\section{Louis Durrive e Yves Schwartz}

Tradutor. Liliana Cunha e Marianne Lacomblez

\section{(2) OpenEdition}

\section{Journals}

\section{Edição electrónica}

URL: http://journals.openedition.org/laboreal/11665

DOI: $10.4000 /$ laboreal. 11665

ISSN: 1646-5237

\section{Editora}

Universidade do Porto

\section{Refêrencia eletrónica}

Louis Durrive e Yves Schwartz, " Glossário da ergologia », Laboreal [Online], Volume 4 Nº1 | 2008,

posto online no dia 01 julho 2008, consultado o 10 dezembro 2020. URL : http://

journals.openedition.org/laboreal/11665 ; DOI : https://doi.org/10.4000/laboreal.11665

Este documento foi criado de forma automática no dia 10 dezembro 2020

\section{cc) (7) (5)}

Laboreal está licenciado com uma Licença Creative Commons - Atribuição-NãoComercial 4.0 Internacional. 


\section{Glossário da ergologia}

Glosario de la ergología

Vocabulaire ergologique

Glossary of ergology

\section{Louis Durrive e Yves Schwartz}

Tradução : Liliana Cunha e Marianne Lacomblez

\section{Introdução}

1 Este glossário diz respeito a uma selecção de conceitos da abordagem ergológica, cujo entendimento poderá facilitar a leitura dos artigos apresentados.

2 Trata-se de definições contextualizadas, não seguindo portanto a lógica de um dicionário com referências que se pretendem definitivas.

\section{Acção e actividade}

3 A acção tem um início e um fim determinados, ela pode ser identificada (gesto, marca), atribuída a uma decisão, sujeita a uma razão (exemplo : uma instrução é uma lista de acções).

4 A actividade é um impulso de vida, de saúde, sem limite predefinido, que sintetiza, cruza e liga tudo o que se representa separadamente (corpo/espírito ; individual/ colectivo ; fazer/valores ; privado/profissional ; imposto/desejado ; etc. ....).

\section{Aderência (local e temporal)}

5 Fenómeno cuja significação, em qualidade e em relação, está estreitamente ligado à situação vivida aqui e agora (em latim hic et nunc: ao momento e ao lugar que se encontra em causa). Falar-se-á de "desaderência conceptual" a propósito, por exemplo, das normas que enquadram a actividade, porque são voluntariamente desligadas do 
aqui e agora. Porque ela solicita, simultaneamente, os dois registos - a grande proximidade da linguagem com a aderência do viver e ao mesmo tempo o distanciamento que ela autoriza, o que é uma relativa desaderência -, o exercício que consiste em falar do seu trabalho é um desafio. Contudo a dificuldade, o desafio aparece apenas aos que ponderaram as múltiplas gestões ou debates de normas inerentes ao agir humano.

\section{Antecipar}

6 Anteceder, tomar a dianteira, ser proactivo. A nossa faculdade humana de formar conceitos permite-nos antecipar em parte o inesperado do trabalho (graças ao prescrito, mas também à formação, à experiência reflectida, herdada de um colectivo e também pessoal).

\section{Arbitragem}

7 Não confundir com o arbitrário, que não tem em conta nenhuma regra. 0 ser humano em actividade não é nem livre de qualquer constrangimento, nem determinado como um robô : ele efectua incessantemente arbitragens que lhe permitem ao mesmo tempo obedecer a um procedimento e transgredi-lo, tendendo a fazer à sua maneira, no aqui e agora. Estas arbitragens supõem critérios mais ou menos conscientes/individuais/ formalizados.

\section{Bem comum}

8 A procura do e de bem(ns) comum(ns) é o horizonte do político [polis : a Cidade]. A actividade humana, mais particularmente o trabalho no sentido estrito, é um espaço onde se retrabalham incessantemente os valores do político cruzados com os valores dimensionados, ou seja, aqueles cujos limites são conhecidos, que se pode medir, quantificar (valores do espaço mercantil).

\section{Bifurcações}

9 Alternativas, micro-escolhas face às quais cada um de nós está constantemente confrontado na sua actividade de trabalho.

\section{Categorias}

10 Trata-se das compartimentações intelectuais que fazemos para tentar circunscrever os fenómenos que analisamos. As categorias são indispensáveis (por exemplo, distinguir a vida privada e a vida profissional), mas elas podem também cegar-nos : a actividade de trabalho não conhece estas fronteiras. Ela transgride em parte as nossas compartimentações (corpo/espírito; fazer/valores; etc. ...) e "descategoriza" parcialmente. 


\section{Comensurabilidade}

11 Duas grandezas que têm uma medida comum ; comparável ; tendo em comum qualquer coisa (que resta a definir : por exemplo, entre duas culturas distintas).

\section{Conceito e vida}

12 O conceito é o instrumento para pensar ; ele permite recortar, definir, generalizar, abstrair-se do presente. A vida, quanto a ela, é um fenómeno inteiro, sintético, específico, profundamente ancorado no presente. Viver, é sempre viver aqui e agora, ainda que esta negociação com o actual suponha um universo de normas antecedentes como recursos e como constrangimentos. Conceito e vida formam uma unidade dialéctica : a vida humana promove a conceptualização para alargar os seus horizontes de domínio do meio - que não é somente um meio ecológico mas um ambiente social, próprio ao ser humano. Se é necessário distinguir o conceito e a vida, convém em contrapartida não os separar. Com efeito, o manuseio das normas antecedentes não é neutro : o universo da conceptualização pode voltar-se contra a vida.

\section{Contraditório}

13 Contraditório não se confunde com incoerente : a vida é contraditória pelo facto de gerar alternativas, o inverso, o oposto, a alteridade ; o que não significa incoerência ou loucura.

\section{Corpo-si}

O trabalho não existe sem alguém que trabalha. É difícil nomear este sujeito porque isso subentenderia que ele se encontraria bem delimitado, definido. Ora, se a actividade é efectivamente conduzida por alguém em carne e osso, - ela inscreve-se em funcionamentos neuro-sensitivos de tal forma complexos que não se consegue dar a volta - esta actividade tem, além disso, prolongamentos que ultrapassam a pessoa física. São solicitados e mesmo incorporados, inscritos no corpo : o social, o psíquico, o institucional, as normas e os valores [do contexto e retrabalhados], a relação às instalações e aos produtos, aos tempos, aos homens, aos níveis de racionalidade, etc.... Este alguém que trabalha - este centro de arbitragens que governa a actividade - pode assim ser designado corpo-si ou corpo-pessoa.

\section{Cultura e incultura}

15 A démarche ergológica tem à partida uma ideia forte da cultura, que não é o privilégio das elaborações linguísticas sábias, mas que se enriquece de todas as transformações geradas pela actividade humana.

16 Todavia esta posição não seria sustentável sem, paralelamente, comportar uma ideia forte de conhecimento para incitar a emergência do máximo de saberes a partir das práticas sociais que, sem isto, ficariam num estado baldio (incultura). Assim cada um 
tem a sua própria forma de incultura : do lado dos produtores em geral mas também do lado dos que têm o domínio de saberes constituídos (incultura nomeadamente em relação ao trabalho).

17 O desafio é que cada um conheça o contributo da culturapatrimónio da humanidade mas que se reconheça também como criador de cultura.

\section{Debate de normas}

Como o ilustra a diferença prescrito e real, a actividade é sempre um debate de normas, de acordo com a perspectiva ergológica. Trata-se, para aquele que faz algo, de um debate entre as normas antecedentes e uma tendência/obrigação da pessoa a renormalizar.

\section{Desconforto intelectual}

19 A tentação é forte, para os que trabalham, de escolher o conforto de um discurso sobre as tarefas que evita que se exponham dando conta da própria actividade. Reciprocamente, a tentação é sem dúvida ainda mais forte para os especialistas do conceito, no conforto de uma torre de marfim da racionalidade intelectual de se satisfazer de modelos que conceberam e dos encadeamentos que imaginaram. 0 desconforto intelectual é uma postura que decorre directamente da concepção ergológica da actividade, (ver : renormalização; dupla antecipação). A actividade não pode nunca deixar-nos confortavelmente instalados em interpretações estabilizadas dos processos e dos valores em jogo numa situação de actividade : daí o erro ergológico por excelência, que consiste em não estar em permanência numa postura de desconforto parcial. Trata-se, pelo contrário, de se deixar incomodar metodicamente ao mesmo tempo nos nossos saberes constituídos e nas nossas experiências de trabalho, a fim de progredir incessantemente nos dois planos.

\section{Dispositivo dinâmico a três pólos (DD3P)}

Tendo em conta que estamos num mundo que transformamos continuamente pela actividade, o regime de produção de conhecimentos tem tanto necessidade dos saberes investidos nesta actividade [e produzidos a diversos graus de aderência] como de saberes organizacionais, académicos, disciplinares - que são já providos de uma forma de codificação. Ora, o diálogo destes dois pólos não se pode fazer frontalmente. Ele supõe uma disponibilidade - que não é natural - dos parceiros que operam provisoriamente e tendencialmente nos dois pólos. É necessário que emerja então um terceiro pólo a fim de fazer trabalhar os dois primeiros de modo cooperativo [humildade e rigor na referência ao saber], de maneira a produzir um saber inédito a propósito da actividade humana.

\section{Dramática de uso de si}

$21 \mathrm{Na}$ origem, um drama - individual ou colectivo - tem lugar quando ocorrem acontecimentos, que quebram os ritmos das sequências habituais, antecipáveis, da vida. 
Daí a necessidade de reagir, no sentido de : tratar esses acontecimentos, "fazer uso de si". Ao mesmo tempo, isto produz novos acontecimentos, por conseguinte, transforma a relação com o meio e entre as pessoas.

A situação é então matriz de variabilidade, matriz de história porque engendra outros possíveis em razão das escolhas a fazer (micro-escolhas) para tratar os acontecimentos. A actividade aparece então como uma tensão, uma dramática.

\section{Dupla antecipação}

Como o ilustra a diferença prescrito e real, a linguagem e a actividade estão em relação de dupla antecipação. A linguagem, particularmente no seu uso delimitado, normalizado [uso de "conceitos"], antecipa a actividade e para isso tem necessidade de fazer como se as coisas fossem relativamente estáveis, invariáveis; a seguir, a actividade, totalmente mergulhada na história em curso, ultrapassa por sua vez a linguagem devido à variabilidade, antecipa o que será necessário depois procurar exprimir em palavras. São dois registos que se encontram em dialéctica permanente. A sua superação recíproca produz sempre mais história, sempre mais saberes.

\section{Epistemicidades}

Propósito de construção de saberes sob a forma de conceitos, olhando para o pólo da desaderência, da disciplina epistémica, do pólo 1 dos DD3P. Segundo o que o ensaio de desaderência, de conceptualização visa dos objectos sem ou em actividade (sem ou com debates de normas), tem-se níveis de epistemicidade diferentes. Um modelo do átomo ou uma reacção química relevam da epistemicidade 1 , um sistema jurídico da epistemicidade 2.

Estes diferentes níveis de epistemicidade constituem a oportunidade de transgressões ou de "usurpações".

Um terceiro nível de epistemicidade, característico do campo das actividades humanas (portanto dos seres "com debates de normas") pode ser localizado pela construção de conceitos, por conseguinte, que ambicionam ser da competência da desaderência, como todo o conceito, mas obrigando-se a sempre considerar o facto das renormalizações na sua abordagem das situações humanas e daí a necessidade de se instruir sempre destas. Os conceitos ergológicos aspiram a ser deste tipo.

\section{Epistémico/transformativo}

O transformativo está ligado ao agir que modifica o estado das coisas ; o epistémico está ligado ao objectivo de conhecer [epistema = ciência]. A armadilha seria crer que há de um lado o conhecimento e do outro a acção (o que numa determinada época deixava pensar que existia de um lado os intelectuais e do outro lado as pessoas que exerciam essencialmente actividades manuais). A actividade, qualquer que ela seja, conjuga ao mesmo tempo o transformativo e o epistémico: o trabalho visto de perto, na abordagem clínica, faz mover e a história e os saberes [sob condição de reconhecer estes saberes], uma vez que o trabalho é necessariamente pensado. 


\section{Ergologia} epistémico corresponde à exigência de trabalho dos conceitos : construi-los, precisálos, complexificá-los libertando-os da aderência local e dos valores que aí são retrabalhados - ou seja, tentando neutralizar [na medida do possível] a dimensão histórica dos fenómenos visados pelos conceitos. 0 ergológico é o movimento inverso : os conceitos são aproximados o mais perto possível da sua aderência local para apreender as configurações de saberes e de valores gerados pela actividade aqui e agora.

\section{Exterritorialidade}

Deriva de certos especialistas que se imaginam estar em certa medida acima da contenda, acima da história humana, em posição de pseudo-neutralidade que lhes daria uma autoridade qualquer para decretar o valor do que vivem os seus semelhantes (integrando geralmente o seu ponto de vista).

\section{Forças de convocação e de reconvocação}

Ter em conta a actividade na produção de saberes tem como consequência instaurar uma cooperação entre as competências disciplinares (saberes organizados, académicos) e os protagonistas da actividade. Estes são ao mesmo tempo "forças de convocação e de reconvocação". Forças de convocação, porque, para transformar um mundo saturado de normas antecedentes (portanto da ordem do conceptual : procedimentos, saberes a dominar...), eles têm necessidade das competências disciplinares, dos saberes armazenados e disponíveis. E forças de reconvocação na medida em que são efectivamente eles quem validarão ou interpelarão de novo os saberes constituídos sobre o ser humano, através das situações de actividade, matrizes de segunda antecipação.

\section{Geral-específico}

O geral reenvia aos conceitos, em relação aos quais é necessário retrabalhar incessantemente a definição, que é necessário complexificar para afinar a sua pertinência. 0 específico reenvia à história em curso : atenção, o específico não é uma redução do geral. Isso seria não ver nele senão a ilustração, o caso particular, que ele

Laboreal, Volume $4 N^{\circ} 1$ | 2008 
representa efectivamente mas não somente. Ele é também complexo, e portanto único : toda a situação de trabalho é específica, dito de outro modo ela é bem mais do que uma modalidade do caso geral. A ergologia é um esforço para pensar ao mesmo tempo o geral e o específico.

\section{História}

A actividade, no sentido ergológico, propõe repensar parcialmente a maneira como o homem está implicado na história e produz história. Como encruzilhada de debates entre, de um lado, normas antecedentes e, do outro lado, constrangimentos e disposições a renormalizar, a actividade é uma matriz incessante de contradições potenciais. Por este facto, ela não cessa de "fazer história".

\section{Historicidade}

Carácter do que é histórico : uma situação de trabalho é histórica no sentido em que não se resume ao que foi previsto (material, procedimento, matérias, efectivos, etc. ...). Há infiltração de história porque os acontecimentos continuam lá, a vida faz a sua obra. o desvio é sob este ângulo irredutível. Pode-se geri-lo melhor, mas não suprimi-lo.

\section{Industrioso}

Que é relativo ao acto de trabalho : o termo de indústria é aqui empregue no sentido de mestria, de habilidade.

Mais genericamente, uma actividade orientada para uma finalidade muda as relações do ser industrioso com o seu meio de vida.

O termo industrioso é voluntariamente vago para evitar a palavra trabalho de que se faz uma representação demasiada rápida.

\section{Macro-, méso-, micro-}

Conforme se raciocina mais ou menos em proximidade da actividade de trabalho, a de alguém, de um ser singular, pode-se distinguir graus de apreensão da vida social : o nível microscópico, que nos conduz para o infinitamente complexo e não para o elementar; o nível macroscópico, que é igualmente complexo mas mais facilmente analisável porque mais elaborado, formalizado ; é o nível das altas esferas de decisão, das grandes correntes planetárias (exemplo : as tendências macroeconómicas actuais) ; por último o nível intermédio, mesoscópico, seria o das instituições tais como as empresas, as administrações, as universidades...

\section{Normas}

39 Norma é uma palavra latina que significa o esquadro. A norma exprime o que uma instância avalia como devendo ser : segundo o caso, um ideal, uma regra, um objectivo, um modelo. Esta instância pode ser exterior ao indivíduo [normas impostas e mais ou 
menos assumidas], como pode ser o próprio indivíduo [normas instauradas na actividade], porque cada um procura ser produtor das suas próprias normas, na origem das exigências que o governam.

Para trabalhar, o ser humano tem necessidade de normas antecedentes (manuais e notas técnicas, regras de gestão, organizacionais, prescrições e instruções, procedimentos, etc.) que, ao mesmo tempo, o constrangem e lhe permitem desenvolver uma actividade singular por renormalizações sucessivas.

\section{Normas antecedentes}

41 As normas antecedentes definem-se em relação ao agir humano, a partir de duas características : a anterioridade e o anonimato. Isso significa duas coisas : primeiro, elas existem antes da vida [industriosa] colectiva que tornaram possível; seguidamente, elas não tomam em consideração a singularidade das pessoas que vão estar encarregues de agir e se instalarão no posto de trabalho [tanto quanto esta noção seja válida]. Ora, se a actividade é efectivamente a forma humana da vida, ela está sempre ancorada no presente (impossível viver em vários lugares ao mesmo tempo, ou em vários tempos) e reenvia sempre a alguém, um corpo-si singular (impossível viver por procuração). Por consequência, a actividade corresponde a um ensaio sempre renovado de alguém único, que volta a agir numa configuração do presente das normas ao mesmo tempo anteriores ao agir e anónimas. Assim, nele levando a contradição a um certo grau, as normas antecedentes tornam possível a actividade humana.

\section{Particular/singular}

O particular é a ilustração de uma faceta do geral ; o singular designa uma combinatória complexa que conduz a realidade única. A actividade de trabalho, qualquer que ela seja, pode analisar-se sob cada um destes dois ângulos.

\section{Protagonistas}

Os protagonistas das situações de trabalho designam todos os actores implicados numa actividade. Não são somente os trabalhadores ou empregados, mas também os quadros, os dirigentes de empresa e mais amplamente ainda os representantes destes actores na vida social à escala macro. Cada um é convidado a uma démarche ergológica para participar na elaboração de saberes e para tirar partido das reservas de alternativas escondidas nas actividades humanas.

\section{Real/realidade}

Por oposição ao que deveria ser ou poderia ser (por exemplo, o que é prescrito ou antecipado no trabalho), o real é o que resiste ao esforço que desenvolvemos para o transformar e/ ou para o conhecer. 
Neste sentido, o real é um horizonte, nunca é inteiramente circunscrito, mas está sempre a sê-lo mais. A realidade seria então a parte do real de que conseguimos uma representação.

\section{Renormalização}

O ser humano, como todo o ser vivo, está exposto a exigências ou normas, emitidas continuamente e em quantidade pelo meio no qual se encontra. Para existir como ser singular, vivo, e em função das lacunas das normas deste meio face às inúmeras variabilidades da situação local, ele vai e deve tentar permanentemente re-interpretar estas normas que lhe são propostas. Fazendo isto, ele tenta configurar o meio como o seu próprio meio. É o processo de renormalização que está no cerne da actividade. Em parte, cada um chega a transgredir certas normas, a distorcê-las de forma a elas se apropriar. Em parte, cada um sofre-as como algo que se impõe do exterior [por exemplo, a linguagem é na actividade um esforço de singularização do sistema normativo que é a língua].

\section{Reservas de alternativas}

47 Um debate de normas conduz a outras maneiras de ver as coisas, a outras perspectivas para viver e agir em conjunto, até ao mais micro dos nossos actos quotidianos, portanto, os mais imperceptíveis. Se as normas exprimem o estabilizado, o antecipado, elas têm vocação para ser colocadas em história graças a homens capazes de renormalização. A partir de lá, vai satisfazer-se de uma aparente reprodução do quadro normativo, ou pelo contrário deixará um espaço e condições para que se exprimam as alternativas em reserva, as que resultam das renormalizações [e que devem ser colocadas em debate na medida em que elas não têm ipso facto vocação para construir um mundo comum] ? A questão reenvia no final ao viver em conjunto e aos desafios da democracia.

\section{Resíduos e penumbra}

48 A renormalização pela actividade é um processo contínuo de história e de saberes parcialmente renovados. As categorias do conhecimento com as quais abordamos a actividade são portanto por definição sempre em parte ultrapassadas por esta. Elas deixam na penumbra elementos de que não se pode a priori dizer que são de importância menor ou maior. A ambição de um dispositivo a três pólos é trabalhar o desvio entre o que está já pensado e o que é manifestado pelo vivido aqui e agora.

Em contrapartida, se se aborda a actividade imaginando que ela é apenas aplicação de modelos já concebidos, negligenciar-se-á os elementos em penumbra como resíduos e é provavelmente um erro.

\section{Saberes investidos}

Noção que reenvia a Dispositivo a Três Pólos e à Dupla antecipação. O encontro da actividade humana coloca-nos face a formas de saberes complexos e híbridos, 
mobilizados em (daí o termo de "investidos") e produtores de renormalizações. Eles são, por conseguinte, convocados na dimensão singular, histórica, não estandardizável, das situações de vida e de trabalho. São marcados por graus diversos de aderência a essas situações, e a sua "mestria" é urdida a estes graus de aderência. Por este facto, os saberes humanos podem situar-se sobre um continuum entre dois pólos, um exprimindo o compromisso numa disciplina da desaderência (ver pólo 1 do DD3P), em relação às condições de espaço, de tempo, de singularidade (no limite, os conceitos e modelos em ciências da matéria); o outro, pelo contrário, exprimindo o ensaio de seguir o mais perto possível as renormalizações das situações de vida e de trabalho (ver pólo 2 do DD3P). Continuum não significa contudo total continuidade e homogeneidade destes saberes situados entre estes dois pólos. Tipos diferentes de epistemicidade localizam-se sobre este continuum.

\section{Sentido do trabalho}

51 O sentido é aqui nomeado, portanto supostamente conhecido ou conhecível : ora ele é problemático. Cada um dá significados múltiplos e moventes ao que vive. Falar de sentido do trabalho, é correr o risco de circunscrever o que não pode sêlo - e eventualmente decretar o sentido em lugar do interessado [cf. tal tarefa é declarada a priori motivante ou não, carregada/ou pelo contrário desprovida de sentido; tal trabalho teria ou não valor].

\section{Uso de si}

52 Todo o trabalho, porque é o lugar de um problema, apela um uso de si. Isto quer dizer que não há simples execução mas uso, convocação de um indivíduo singular com capacidades bem mais amplas que as enumeradas pela tarefa. Trabalhar coloca em tensão o uso de si requerido pelos outros e o uso de si consentido e comprometido por si mesmo.

\section{Valores}

53 No sentido subjectivo, é o peso que se atribui mais ou menos às coisas ; uma hierarquia, uma categorização própria a cada um a propósito do que se estima, prefere, ou pelo contrário que se negligencia, rejeita. Em certa medida, é a tentativa de cada um de ter uma mestria sobre o meio no qual se encontra (exemplo : um escritório personalizado). o indivíduo não inventa sozinho nem completamente os seus valores, mas retrabalha incessantemente os que o meio lhe propõe. Nisso, pelo menos parcialmente, ele singulariza-os.

\section{Valores dimensionados}

Os valores dimensionados são aqueles cujos limites são conhecidos, que correspondem a medidas, a quantidades: aqueles do espaço nomeadamente ocupado pelo mercado mas também através das avaliações, critérios e indicadores quantitativos. Por oposição, os valores não dimensionados são os do político, do "bem comum" (a saúde, a educação) 
num "mundo de valores" onde não há nem limitação interna clara entre eles, nem hierarquização possível. Uns são trabalhados pelos outros. No pólo do político, a saúde, a educação passam pela alocação de meios concretos, portanto necessariamente limitados. Reciprocamente, não é suposto a gestão de um hospital funcionar unicamente à calculadora mas também em nome de valores de universalidade.

\section{AUTORES}

\section{LOUIS DURRIVE}

Université Louis Pasteur de Strasbourg, 4 rue Blaise Pascal F-67070 Strasbourg Cedex

L'association L'Atelier, BP 952, 67029 Strasbourg

atelier.durrive@wanadoo.fr

\section{YVES SCHWARTZ}

Université de Provence ; Département d'Ergologie-Analyse Pluridisciplinaire des Situations de travail 29 Avenue R. Schumann, 13 100, Aix-en-Provence Cedex, France yves.schwartz@univprovence.fr 